\title{
Simultaneous Determination of NSAID and Antimicrobial Preservatives Using Validated RP-HPLC Method: An Application in Pharmaceutical and Clinical Laboratories
}

\author{
Najmul Hasan ${ }^{1 *}$, Mathurot Chaiharn ${ }^{2}$, Shabana Naz Shah ${ }^{3}$, Hira Khalid ${ }^{4}$ and Abdul Jabbar \\ ${ }^{1}$ Department of Microbiology, Faculty of Science, University of Karachi, Karachi-75270, Pakistan \\ ${ }^{2}$ Division of Biotechnology, Faculty of Science, Maejo University, Chiang Mai 50290, Thailand \\ ${ }^{3}$ Department of Pharmaceutical Chemistry, Research Institute of Pharmaceutical Sciences, Faculty of Pharmacy, University of Karachi, Karachi-75270, Pakistan \\ ${ }^{4}$ Department of Chemistry, Government College University, Lahore Pakistan, 54000 \\ ${ }^{5}$ Provincial TB Control reference laboratory, National TB control Programme Peshawar, Pakistan
}

\begin{abstract}
A stability indicating, accurate, specific, precise and simple high performance liquid chromatographic method has been developed and validated for the simultaneous determination of Dexibuprofen along with its preservatives i.e. Sodium Benzoate, Methylparaben, and Propylparaben in pharmaceutical dosage forms of oral solution and in serum. Acetonitrile: Acetate Buffer: Acetic Acid (0.1 M) (50:50:0.3 v/v/v) $(\mathrm{pH} 5.5)$ was the mobile phase at flow rate $1.0 \mathrm{~mL} \mathrm{~min}^{-1}$ using a Hibar ${ }^{\circledR} \mu$ Bondapak $^{\circledR} \mathrm{C}_{18}$ column monitored at wavelength of $230 \mathrm{~nm}$. The calibration curve was linear with a correlation coefficient of more than 0.9995 for the drugs. The averages of the absolute and relative recoveries were found to be $100.07 \%, 99.82 \%, 99.91 \%$ and $99.97 \%$ for Dexibuprofen, Sodium Benzoate, Methylparaben and Propylparaben respectively with 5 to $25 \mathrm{ng} \mathrm{mL}^{-1}$ limit of quantification and 1.5 to $7 \mathrm{ng} \mathrm{mL}^{-1}$ limit of detection. The drugs were subjected to stress conditions of hydrolysis (acid, base, oxidation, and thermal degradation). Maximum degradation was observed in base and $35 \% \mathrm{H}_{2} \mathrm{O}_{2}$ while found almost stable in the other stress conditions. The studies of forced degradation prove the stability indicating power of the method. The developed method was validated in accordance to $\mathrm{ICH}$ guidelines.
\end{abstract}

The proposed High-performance liquid chromatographic method was successfully applied to quantify the amount of Dexibuprofen and three most common microbial preservatives in bulk, dosage form and physiological fluid.

Keywords: Dexibuprofen; Oral solution; Paraben; Benzoate; RPHPLC; Serum

Abbreviations: MP: Methylparaben; PP: Propylparaben; SBZ: Sodium benzoate; DBPN: Dexibuprofen; HPLC: High Performance Liquid Chromatography; ICH: International Conference on Harmonisation; NSAID: Non-Steroidal Anti-Inflammatory Drug

\section{Introduction}

Dexibuprofen (DBPN, Figure 1) is the pharmacologically effective (S+ Enantiomer of Ibuprofen) and chemically is 2-[4-(2-methylpropyl) phenyl] propanoic acid [1]. In contrast to Ibuprofen the administration of dexibuprofen may offer the advantage of delivering the well-known antipyretic, analgesic and anti-inflammatory properties of ibuprofen in a more efficient way, with a better safety profile than the racemic ibuprofen formulations [2]. It is a widely used as nonsteroidal antiinflammatory and analgesic agent for many years $[3,4]$ and for the symptomatic treatment of osteoarthritis, primary dysmenorrhoea,

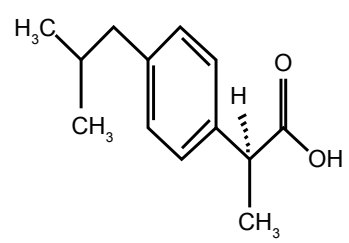

DBPN

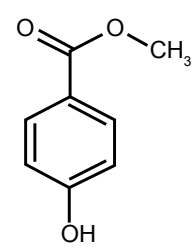

MP

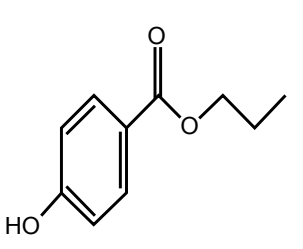

PP
Figure 1: Chemical structures of Dexibuprofen (DBPN) Methylparaben (MP) and Propylparaben (PP). muscular skeletal pain or dental pain and reduces gastric damage and improves analgesic and anti-inflammatory effect than racemic ibuprofen [5]. Dexibuprofen is rapidly absorbed, and peak serum concentration is achieved within 1.5-2 hours of oral administration [6]. It has been established there is a significant correlation between serum Dexibuprofen levels and the resultant degree of pain relief, particularly 1 hour after administration [7].

Methylparaben $\left(\mathrm{C}_{8} \mathrm{H}_{8} \mathrm{O}_{3}\right)$ (MP Figure 1) Propylparaben $\left(\mathrm{C}_{10} \mathrm{H}_{12} \mathrm{O}_{3}\right)$ (PP, Figure 1) and Sodium benzoate $\mathrm{NaC}_{6} \mathrm{H}_{5} \mathrm{CO}_{2}$ are the well-known preservatives that are used primarily for their bactericidal and fungicidal properties. Parabens that include MP and PP, are a group of the alkyl esters of p-hydroxybenzoic acid, have a low toxicity profile and a long history of use. It readily absorbed from the gastrointestinal tract or through the skin [8]. Usage of MP is toxic at higher concentrations, has an estrogenic effect [9]. The estrogenic activity of parabens increases with the length of the alkyl group and is believed that PP is estrogenic to a certain degree as well [10]. Sodium

*Corresponding author: Najmul Hasan, Department of Microbiology, Faculty of Science, University of Karachi, Karachi-75270, Pakistan, Tel: 0092-333-366-9331; E-mail: najam.edu.pak@gmail.com

Received Januray 28, 2013; Accepted August 05, 2013; Published August 22, 2013

Citation: Hasan N, Chaiharn M, Shah SN, Khalid H, Jabbar A (2013) Simultaneous Determination of NSAID and Antimicrobial Preservatives Using Validated RPHPLC Method: An Application in Pharmaceutical and Clinical Laboratories. Pharm Anal Acta 4: 263. doi:10.4172/2153-2435.1000263

Copyright: $\odot 2013$ Hasan N, et al. This is an open-access article distributed under the terms of the Creative Commons Attribution License, which permits unrestricted use, distribution, and reproduction in any medium, provided the original author and source are credited. 
Citation: Hasan N, Chaiharn M, Shah SN, Khalid H, Jabbar A (2013) Simultaneous Determination of NSAID and Antimicrobial Preservatives Using Validated RP-HPLC Method: An Application in Pharmaceutical and Clinical Laboratories. Pharm Anal Acta 4: 263. doi:10.4172/21532435.1000263

Page 2 of 7

benzoate (SBZ) as a cheap preservative inhibits bacteria, mold \& yeast under acidic condition. The Food and Drug Administration limits sodium benzoate to concentrations of $0.1 \%$ by weight. Therefore for the reassessment of the safety and significance of these preservatives a new, simple method was needed to develop along with effective Dexibuprofen.

Literature survey reveals some analytical methods for Dexibuprofen including High-Performance Liquid Chromatographic (HPLC) determination of Dexibuprofen in St. John's Wort [11-13], in human serum and other physiologic fluids by HPLC/HPLC-mass spectrometry [14-19], by radian compression technique [20].

Some methods of analysis of MP, PP either alone or in some other formulations are available including High-Performance Liquid Chromatographic (HPLC) i.e. [21-32], gradient HPLC [33], solid phase extraction HPLC [34], HPLC-MS [35].

However to the best of our extensive research survey revealed that till now no stability indicating HPLC method is available which can determine the four ingredients concomitantly, therefore an endeavor was made to develop a simple, sensitive and validated stability indicating RP-HPLC method using UV detection to determine Dexibuprofen along with its essential microbial preservatives in pharmaceutical dosage forms and human serum. The present work deals with method development, method validation and forced degradation study of the ingredients. The applicability of the method was confirmed for analysis in pharmaceutical products and for pharmacokinetic studies. The results of analysis were validated in accordance with $\mathrm{ICH}$ guidelines [36].

\section{Materials and Methods}

The present method was designed to be easy to use, sensitive, rapid and simple sample preparation for the active and preservatives ingredients. Separation and quantification in pharmaceutical drug formulations and blood were achieved with an isocratic elution.

\section{Reagents and chemicals}

Dexibuprofen, Sodium Benzoate, Methylparaben, Propylparaben were kind gifts from National Pharmaceuticals, whereas sulphuric acid, sodium heptane sulphonate, Acetonitrile (HPLC grade) were purchased from Merck (Germany). The pharmaceutical dosage forms containing the respective ingredients were obtained from commercial source $\left(\mathrm{DESOMIN}^{\circledR}\right.$, DEXACT $^{\circledR}$, DEXIB $^{\circledR}$, and ZIBUFEN ${ }^{\circledR}$ ) labeled to contain $20 \mathrm{mg} \mathrm{mL}^{-1}, 0.5 \mathrm{mg} \mathrm{mL}^{-1}, 0.2 \mathrm{mg} \mathrm{mL}^{-1}$ and $0.1 \mathrm{mg} \mathrm{mL}^{-1}$ of DBPN, SBZ, MP \& PP respectively. Distilled water was obtained by passage through RO plant (Waterman, Pakistan) and was further filtered through a $0.45 \mu \mathrm{m}$ membrane filter (Millipore, Bedford, MA, USA).

\section{Instruments}

For chromatography a SIL 10A auto injector HPLC system comprising of SCL 10A system controller, SPD 20A prominence UV/VIS detector, and Shimadzu LC 20 AT pump with LC Solutions software was used. Separation was performed on a Hibar ${ }^{\mathbb{R}} \mu$ Bondapak $^{\mathbb{R}}$ ODS C18 HPLC column, $(4.6 \times 250 \mathrm{~mm} ; 5 \mu \mathrm{m}$ bead size $)$ maintained at $25^{\circ} \mathrm{C}$. A UV-visible Shimadzu 16500 PC spectrophotometer with UV Probe software, ultrasonic cleaner (Elmasoni E $60 \mathrm{H}$ ), Jenway 3240 $\mathrm{pH}$ meter and Sartorious TE2145 analytical balance were used in the research work. Throughout the work only amber glass flasks were used to avoid light effect on the solutions of DBPN, SBZ, MP \& PP standards and samples.

\section{Chromatographic conditions}

The HPLC analysis was carried out at ambient temperature. The compound was chromatographed isocratically with a mobile phase consisting of Acetonitrile (HPLC grade): Acetate Buffer $0.1 \mathrm{M}$ (Disodium hydrogen phosphate): Acetic Acid 0.1M (50:50:0.3, v/v/v) with the apparent $\mathrm{pH}$ adjusted if required to $5.5 \pm 0.1$ using Acetic Acid $0.1 \mathrm{M}$. The mobile phase was filtered by passing through a 0.45 $\mu \mathrm{m}$ membrane filter (Millipore, Bedford, MA, USA). The flow rate was $1.0 \mathrm{~mL} \mathrm{~min}^{-1}$, and the injected volume was $20 \mu \mathrm{L}$. The effluent was monitored spectrophotometrically at wavelength of $230 \mathrm{~nm}$. Mobile Phase was used as dilution solvent.

\section{Analytical procedure}

Standard preparation: SBZ, MP\& PP reference standard were accurately weighed as $50 \mathrm{mg}, 20 \mathrm{mg}$ and $10 \mathrm{mg}$ in $100 \mathrm{ml}$ flask and dissolved in diluent to have a stock solution-A of $500 \mu \mathrm{g} \mathrm{mL}{ }^{-1}, 200 \mu \mathrm{g}$ $\mathrm{ml}^{-1}$ and $100 \mu \mathrm{g} \mathrm{mL} \mathrm{L}^{-1}$ respectively, while in another $100 \mathrm{ml}$ volumetric flask, accurately $100 \mathrm{mg}$ of DBPN was weighed and dissolve in $70 \mathrm{ml}$ of dilution solvent sonicated for 5 minutes and then added by $5 \mathrm{ml}$ of the stock solution-A and filled up to the mark with dilution solvent to get stock solution-B containing $1000 \mu \mathrm{g} \mathrm{mL}^{-1}$ of DBPN, $25 \mu \mathrm{g} \mathrm{mL} \mathrm{m}^{-1}$ of SBZ, $10 \mu \mathrm{g} \mathrm{mL} L^{-1}$ of MP and $5 \mu \mathrm{g} \mathrm{mL}^{-1}$ of PP. The solution-B was used in further analytical steps.

\section{Sample preparation}

Assay of suspension containing the drug: For making a sample from suspension, 10 bottles were opened and content was mixed to get an evenly homogenized stock sample. The sample density was determined and then sample weight accurately equivalent to $5 \mathrm{ml}$ was taken in $200 \mathrm{ml}$ volumetric flask and $100 \mathrm{~mL}$ of diluent was added. The sample was sonicated for 5 minutes and then added diluent up to the mark, placed on stirrer for 10 minutes. The sample was then filtered through $0.45 \mu \mathrm{m}$ filter paper and injected into the HPLC system.

Sample preparation for serum: Blood samples were collected from healthy volunteers in evacuated glass tube through an indwelling cannula placed on forearm vein by a trained clinical laboratory technician. The volunteers were not involved in any medication, smoking, and strenuous activity. The blood was shaken and centrifuged at $10,000 \mathrm{rpm}$ for $10 \mathrm{~min}$ to separate out serum. Acetonitrile was added to serum $(90: 10, \mathrm{v} / \mathrm{v})$ and centrifuged at $10,000 \mathrm{rpm}$ for $10 \mathrm{~min}$ to deprotonated it. The serum thus obtained was filtered and used for the analysis and were stored at $20^{\circ} \mathrm{C}$. For making working sample $10 \mathrm{ml}$ of stock solution-B was taken in $20 \mathrm{ml}$ flask, followed by $5 \mathrm{ml}$ of serum. The sample thus obtained was stir for 10 minutes and then added diluent up to the mark. Triplicate solutions were made for each working solution for the analysis in serum, was filtered through $0.45 \mu \mathrm{m}$ filter paper and injected into the HPLC system.

Assay of suspension for degradation studies of drugs: For this purpose $25 \mathrm{ml}$ of stock solution-B was diluted in four individual 50 $\mathrm{mL}$ volumetric flasks and $15 \mathrm{~mL}$ of degrading agent were added to each flask individually, with exception of one to which only diluent was added; these included $0.1 \mathrm{M} \mathrm{HCl}, 0.1 \mathrm{M} \mathrm{NaOH}, 35 \% \mathrm{H}_{2} \mathrm{O}_{2}$ and then to each flask diluent was added up to the mark. All the four samples were placed in water bath at $60^{\circ} \mathrm{C}$ for one hour. The samples were then filtered through $0.45 \mu \mathrm{m}$ filter paper and injected into the HPLC system.

\section{Stability studies}

For stability studies the commercially available suspension samples 
Citation: Hasan N, Chaiharn M, Shah SN, Khalid H, Jabbar A (2013) Simultaneous Determination of NSAID and Antimicrobial Preservatives Using Validated RP-HPLC Method: An Application in Pharmaceutical and Clinical Laboratories. Pharm Anal Acta 4: 263. doi:10.4172/21532435.1000263

Page 3 of 7

were placed at accelerated conditions of temperature that is at $40^{\circ} \mathrm{C}$ with $75 \%$ relative humidity and at ambient conditions of $30^{\circ} \mathrm{C}$ temperature with $65 \%$ relative humidity in environmental chamber for six months. The stability protocol showed elsewhere was followed for six months and assays were made as described in method development.

Intentional degradation was attempted to stress conditions exposing the drugs with acid $(0.1 \mathrm{~N} \mathrm{HCl})$, alkali $(0.1 \mathrm{~N} \mathrm{NaOH})$, hydrogen peroxide $(35 \%)$ and heat $\left(60^{\circ} \mathrm{C}\right)$ to evaluate the ability of the proposed method to separate drugs from its degradation products. For all conditions the heat temperature was kept constant at $60^{\circ} \mathrm{C}$ for a period of one hour.

\section{Method validation}

The method validation was performed in following ICH guideline [36] according to which the assay validation was performed via various procedures including specificity, linearity, range, accuracy, intra-day and inter-day precision etc.

To study the linearity of standard solutions, twenty dilutions were prepared from stock solution-B to give standard solutions in range of $10 \%$ to $200 \%$ of drugs content. The standard calibration curve was generated using regression analysis. For specificity commonly used excipient in suspension preparation were spiked in a pre-weighed quantity of drugs and then peak areas were measured and calculations done to determine the quantity of the drugs recovered.

The precision was by analyzing corresponding standard daily for a period of three days i.e. Inter-day precision, and three times a day with an interval of 8 hours (Intra-day precision) against freshly prepared standard solutions. For determining accuracy the reference standards were accurately weighed and added to the suspension sample, to get three different concentration levels i.e. $80 \%-100 \%-120 \%$ of the ingredients. At each level, samples were prepared in triplicate and the recovery percentage was determined.

Limit of detection and quantification (LOD \& LOQ) for the method were established by sequential diluting the standard solutions at decreasing concentrations, in the range of $100 \mathrm{ng} \mathrm{mL}^{-1}$ to $1 \mathrm{ng} \mathrm{mL}^{-1}$ and injected onto the chromatographic system. The limit of detection was defined as the concentration for which a signal-to-noise ratio of 3 was obtained and, for quantification limit; a signal-to-noise ratio of 10 was considered.

The robustness was studied by analyzing the same samples of suspension by deliberate variation in the method parameters, such as in the chromatographic conditions, like mobile phase, $\mathrm{pH}$, flow rate, temperature etc. System suitability of the method was evaluated by analyzing the symmetry of the standard peaks, resolution and theoretical plates of the column.

\section{Results and Discussion}

The HPLC method development and its validation are the utmost requirements for any drug available in the market to have high quality products. A few methods are available for determination of the DBPN as described earlier, but many of them are used only for certain definite objectives and none can be generalized for its simultaneous determination with preservatives in form of pharmaceutical products and serum. Similarly none of them is as much sensitive as ours is; in terms of its Precision, accuracy, \%recovery, limit of detection (LOD) and limit of quantification (LOQ). Moreover this method is sensitive enough to be used for pharmacokinetic studies as its LOD \& LOQ are in nanogram range.

\section{Method development \& optimization}

For developing an efficient method for analysis, parameters, such as detection wavelength, mobile phase composition, optimum $\mathrm{pH}$ and concentration of the standard solutions were comprehensively studied. All the ingredients were diluted in dilution solvent and then run through UV spectrophotometer in UV range of $190 \mathrm{~nm}-400$ $\mathrm{nm}$ to get maximal wavelengths, where maximum absorbance was gained i.e. $266 \mathrm{~nm}, 220 \mathrm{~nm}$, and $254 \mathrm{~nm}$ for DBPN, SBZ and MP \& PP respectively. However considering the difference of concentration of the ingredients and intensity of their absorbance a single wavelength method was adopted, that is $230 \mathrm{~nm}$ at which all the molecules gave a satisfactory absorbance. The chromatographic parameters were evaluated using a $\operatorname{Hibar}^{\circledR} \mu \mathrm{Bondapak}^{\circledR} \mathrm{C} 18$ column. Mobile phase of an already developed method by our research team [37] was selected in terms of its components and their proportions and was modified. The mobile phase composed of Acetonitrile: Buffer of previously mentioned proportion promoted a short run time (20 min) as shown in (Figure 2), so this condition was adopted in subsequent analysis.

\section{Validation studies}

The linearity was determined in the range of $10 \%-200 \%$ for all ingredients. The assay was judged to be linear as the correlation coefficient was greater than 0.995 in all cases, calculated by the leastsquare method. A linear correlation was found between the peak areas and the concentrations, in the assayed range. The regression analysis data are presented in Table 1.

Chromatogram shown in Figure 3 proves specificity or selectivity of the assayed method, as the chromatograms in samples were found identical with standard chromatogram and no interference peak was observed. Peak purities higher than $98.0 \%$ were obtained in the chromatograms of sample solutions, demonstrating that other compounds did not co-elute with peaks of interest. The chromatogram obtained with the mixture of the suspension excipient proves that there is no interference from excipient and peak of interest fulfill all the requirements of symmetrical peak, and hence the specificity is confirmed.

The precision of an analytical method is the degree of coherence among individual test results when the method is applied repeatedly to multiple sampling of homogeneous bulk. Intra-day precision of the method was evaluated at three different independent concentrations i.e. $80 \%, 100 \%$, and $120 \%$ for the drugs $(n=3)$ by determining their assays. Inter-day precision of the method was tested for 3 days at the same

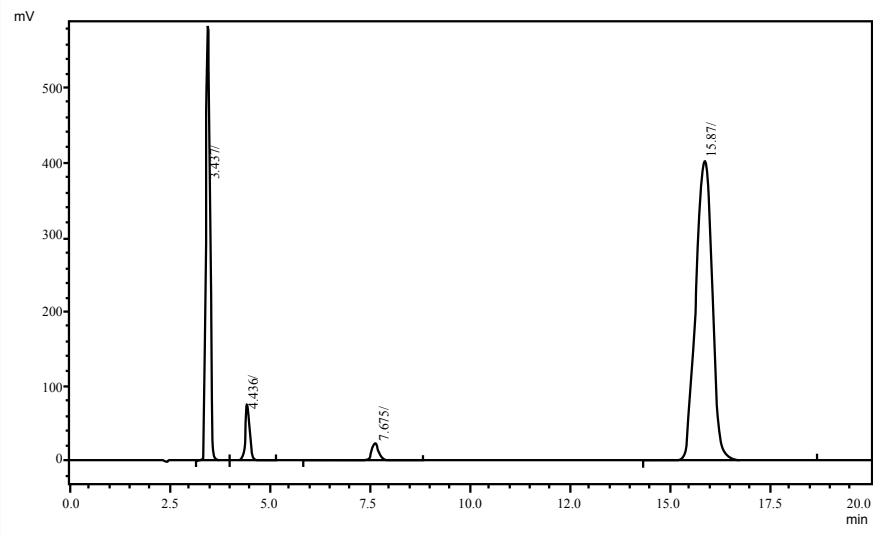

Figure 2: Typical chromatogram of standard. 
Citation: Hasan N, Chaiharn M, Shah SN, Khalid H, Jabbar A (2013) Simultaneous Determination of NSAID and Antimicrobial Preservatives Using Validated RP-HPLC Method: An Application in Pharmaceutical and Clinical Laboratories. Pharm Anal Acta 4: 263. doi:10.4172/21532435.1000263

Page 4 of 7

concentration levels. Solutions for calibration curves were prepared every day on freshly basis. Since the inter-day and intra-day precision obtained \%RSD was less than $2 \%$ it assures that the proposed method is quite precise and reproducible as shown in Table 2.

The accuracy was investigated by means of addition of reference standards to a mixture of the suspension excipients. Recovery studies of the drug were carried out for the accuracy parameter at three different concentration levels i.e. multiple level recovery studies. A known amount of API's standards were added into pre-analyzed sample and subjected to the proposed HPLC method. The mean recovery $(\mathrm{n}=9)$ was 99.46\%-100.65\% for DBPN, 99.44\%-100.58\% (RSD=0.77\%) for SBZ, 98.96\%-100.48\% (RSD=0.95\%) for MP and for PP $99.40 \%-100.53 \%$ $(\mathrm{RSD}=0.95 \%)$, demonstrating the accuracy of the method. Percentage recoveries for marketed products were found to be within the limits (Table 3).

The statistical analysis showed no significant difference between results obtained employing the analytical conditions established for the method and those obtained in the experiments in which variations of some parameters were introduced. The parameters used in system suitability test were symmetry of peaks, tailing factor, resolution and RSD of peak area for replicate suspension. Thus, the method showed to be robust for changes in mobile phase Acetonitrile proportion, mobile phase $\mathrm{pH}$, flow rate, and column temperature (Table 4).

Stability testing is an important part of the process of drug product development. The purpose of stability testing is to provide evidence of how the quality of a drug substance or drug product varies with time under a variety of environmental conditions, for example temperature, humidity, and light and enables recommendation of storage conditions, retest periods, and shelf life to be established. The two main aspects of drug product that play an important role in shelf-life determination are assay of the active drug and the degradation products generated during stability studies. The proposed assay method was applied to stability study of commercially available suspension, for which the samples were placed at $30^{\circ} \mathrm{C}$ with relative humidity of $65 \%$ and at $40^{\circ} \mathrm{C}$ with relative humidity of $75 \%$. Stability study was performed according to

\begin{tabular}{|c|c|c|c|c|}
\hline \multirow{2}{*}{ Parameter } & \multicolumn{4}{|c|}{ Inference } \\
\hline & SBZ & MP & PP & DBPN \\
\hline Linearity range $(\mu \mathrm{g} / \mathrm{ml})$ & $1.25-25$ & $0.5-100$ & $0.25-50$ & $50-1000$ \\
\hline Intercept(c) & -5155.365 & 0 & 0 & 0 \\
\hline Standard Regression equation $(y=m x+c)$ Slope $(m)$ & $3004.60 \times-5155.365$ & $1106.39 x+0$ & $1155.24 x+0$ & $2202.41 x+0$ \\
\hline Correlation coefficient $\left(\mathrm{R}^{2}\right)$ & 0.99986 & 0.99967 & 0.99952 & 0.99961 \\
\hline Limit of detection (LOD) (ng /ml) & 3 & 7 & 5 & 1.5 \\
\hline Limit of quantification (LOQ) (ng /ml) & 10 & 25 & 15 & 5 \\
\hline
\end{tabular}

Table 1: Calibration curve data and validation parameters.

\begin{tabular}{|c|c|c|c|c|c|c|}
\hline Active Drugs & Nominal Concentration $(\mu \mathrm{g} / \mathrm{ml})$ & Day 1 & Day 2 & Day 3 & Mean & Inter-Day RSD\% \\
\hline \multirow{5}{*}{ DBPN } & 400 & $99.74 \%$ & $100.38 \%$ & $98.86 \%$ & $99.66 \%$ & 0.765 \\
\hline & 500 & $100.65 \%$ & $100.96 \%$ & $100.00 \%$ & $100.53 \%$ & 0.487 \\
\hline & 600 & $101.57 \%$ & $98.95 \%$ & $99.51 \%$ & $100.01 \%$ & 1.380 \\
\hline & Mean & $100.65 \%$ & $100.09 \%$ & $99.46 \%$ & $100.07 \%$ & \\
\hline & Intra-Day RSD\% & 0.91 & 1.03 & 0.58 & 0.44 & \\
\hline \multirow{5}{*}{ SBZ } & 10 & $100.78 \%$ & $99.65 \%$ & $99.74 \%$ & $100.06 \%$ & 0.628 \\
\hline & 12.5 & $99.74 \%$ & $100.38 \%$ & $98.86 \%$ & $99.66 \%$ & 0.765 \\
\hline & 15 & $101.21 \%$ & $98.30 \%$ & $99.71 \%$ & $99.74 \%$ & 1.459 \\
\hline & Mean & $100.58 \%$ & $99.44 \%$ & $99.44 \%$ & $99.82 \%$ & \\
\hline & Intra-Day RSD\% & 0.75 & 1.06 & 0.50 & 0.21 & \\
\hline \multirow{5}{*}{ MP } & 4 & $99.44 \%$ & $100.83 \%$ & $99.50 \%$ & $99.92 \%$ & 0.786 \\
\hline & 5 & $100.28 \%$ & $99.92 \%$ & $98.99 \%$ & $99.73 \%$ & 0.664 \\
\hline & 6 & $101.15 \%$ & $100.70 \%$ & $98.39 \%$ & $100.08 \%$ & 1.480 \\
\hline & Mean & $100.29 \%$ & $100.48 \%$ & $98.96 \%$ & $99.91 \%$ & \\
\hline & Intra-Day RSD\% & 0.85 & 0.49 & 0.56 & 0.18 & \\
\hline \multirow{5}{*}{ PP } & 2 & $99.65 \%$ & $99.81 \%$ & $100.98 \%$ & $100.15 \%$ & 0.725 \\
\hline & 2.5 & $98.56 \%$ & $101.24 \%$ & $100.62 \%$ & $100.14 \%$ & 1.401 \\
\hline & 3 & $99.98 \%$ & $100.54 \%$ & $98.40 \%$ & $99.64 \%$ & 1.114 \\
\hline & Mean & $99.40 \%$ & $100.53 \%$ & $100.00 \%$ & $99.97 \%$ & \\
\hline & Intra-Day RSD\% & 0.75 & 0.71 & 1.40 & 0.29 & \\
\hline
\end{tabular}

Table 2: Inter-day and intra-day precision and recovery studies.

\begin{tabular}{|l|c|c|c|}
\hline \multirow{2}{*}{ SAMPLES } & \multicolumn{2}{|c|}{ Content (\%) \pm S.D. } \\
\cline { 2 - 4 } & DBPN & SBZ & $97.77 \% \pm 0.73$ \\
\hline Desomin $^{\circledR}$ & $99.75 \% \pm 0.19$ & $99.87 \% \pm 0.69$ & $99.78 \% \pm 0.11$ \\
\hline Dexact $^{\circledR}$ & $98.91 \% \pm 0.81$ & $100.62 \% \pm 0.97$ & $99.91 \% \pm 0.34$ \\
\hline Dexib $^{\circledR}$ & $100.12 \% \pm 0.51$ & $97.18 \% \pm 0.38$ & $99.95 \% \pm 0.45$ \\
\hline Zibufen $^{\circledR}$ & $99.43 \% \pm 0.12$ & $98.72 \% \pm 0.43$ & $100.35 \% \pm 0.25$ \\
\hline
\end{tabular}

SD $=$ Standard Deviation

Table 3: Contents of DBPN, SBZ, MP and PP in the fixed dose combination suspension. 
Citation: Hasan N, Chaiharn M, Shah SN, Khalid H, Jabbar A (2013) Simultaneous Determination of NSAID and Antimicrobial Preservatives Using Validated RP-HPLC Method: An Application in Pharmaceutical and Clinical Laboratories. Pharm Anal Acta 4: 263. doi:10.4172/21532435.1000263

stability protocol as described in previous section (Table 5). Samples were analyzed and percentage of contents was measured. According to the results obtained DBPN with all the three preservatives were found to be stable at applied conditions of temperature and relative humidity, and were accurately analyzed with the proposed method.

During the degradation study upon treatment of DBPN, SBZ, MP and $\mathrm{PP}$ with base $(0.1 \mathrm{M} \mathrm{NaOH})$, acid $(0.1 \mathrm{M} \mathrm{HCl})$, hydrogen peroxide $(35 \%)$ and heat it was observed that DBPN with preservatives is fairly stable to acid and heat (Figure 4 and 5). Esters of MP, PP and salt of carboxylic acid showed thermally stability and no decarboxylation occurs to DBPN up to this temperature. Also with dilute mineral acid most suspected reaction of sodium benzoate by reforming carboxylic acid could be possible but shows no peculiar change in absorbance pattern of its chromophore. The data in Table 6, also revealed that SBZ and DBPN are usually more vulnerable to the stress conditions as compared to MP and PP. Further in Figure 6, base treated sample,

\begin{tabular}{|l|c|c|c|c|c|}
\hline & & \multicolumn{4}{|c|}{ Retention time } \\
\cline { 3 - 6 } Chromatographic Conditions & Variation & DBPN & SBZ & MP & PP \\
\hline \multirow{3}{*}{ Temperature $\left({ }^{\circ} \mathrm{C}\right)$} & 22 & 15.781 & 3.337 & 4.235 & 7.543 \\
\hline \multirow{3}{*}{ Flow rate $(\mathrm{ml} / \mathrm{min})}$. & 30 & 17.019 & 3.598 & 4.712 & 8.135 \\
\hline \multirow{2}{*}{ Amount of Acetonitrile (\%) } & 0.8 & 20.949 & 4.426 & 5.842 & 9.936 \\
\hline & 1.2 & 13.960 & 2.937 & 3.882 & 6.638 \\
\hline & 48 & 15.972 & 3.543 & 4.566 & 7.782 \\
\hline
\end{tabular}

Table 4: Robustness of the method.

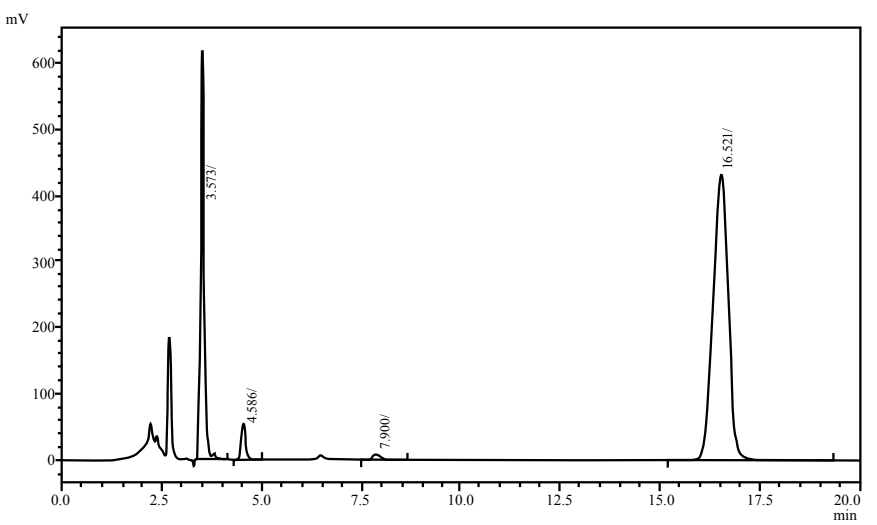

Figure 3: Typical chromatogram of physiological sample.

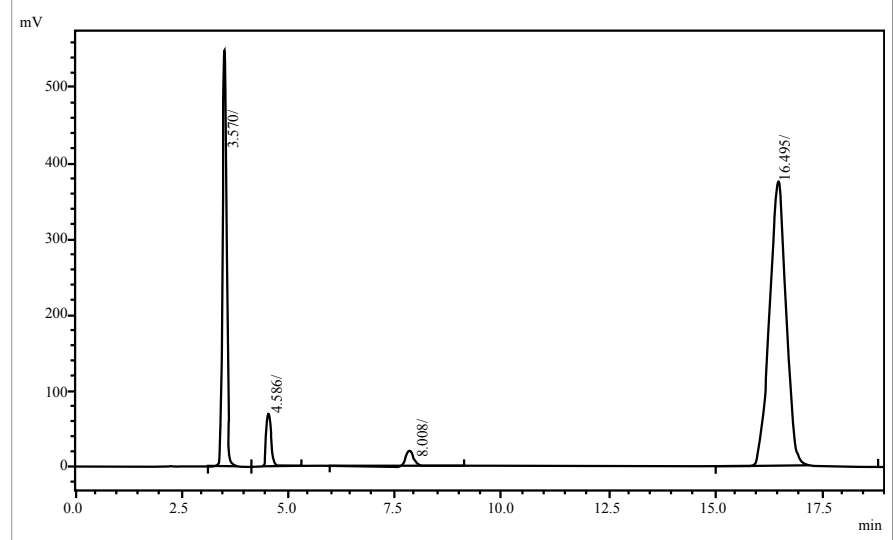

Figure 4: Typical chromatogram of heat treated sample.

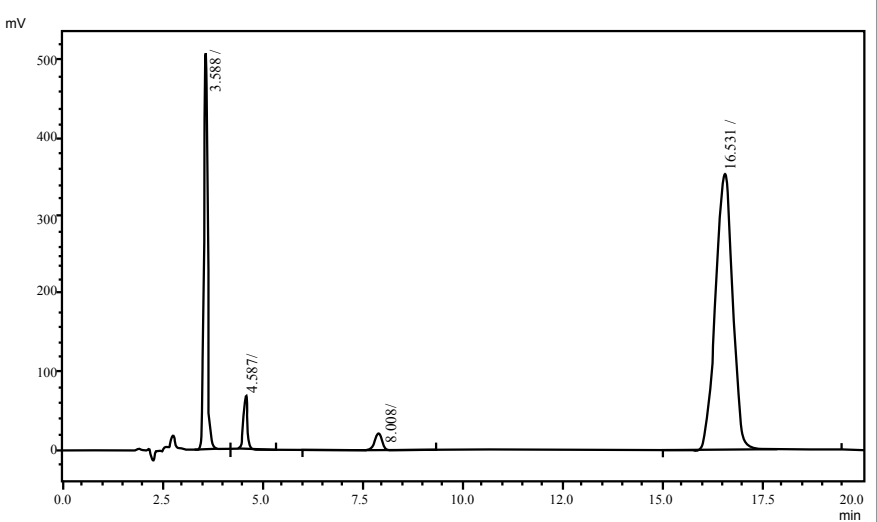

Figure 5: Typical chromatogram of acid treated sample.

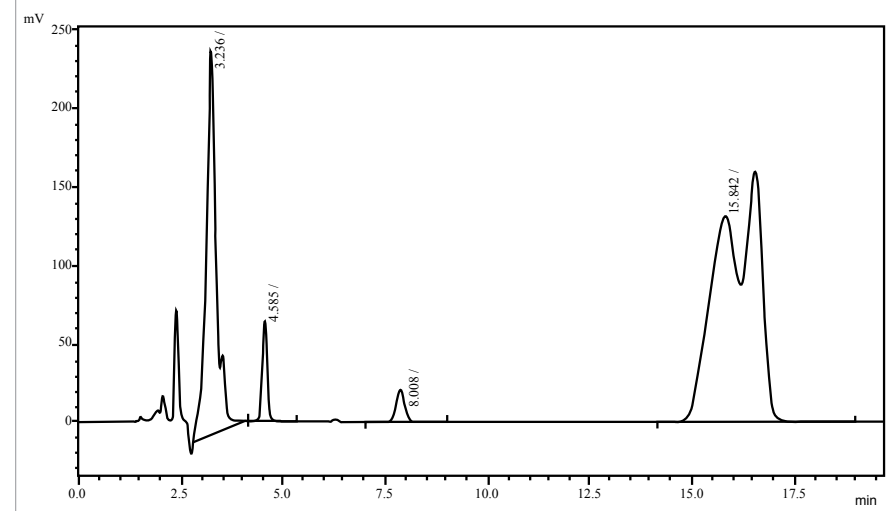

Figure 6: Typical chromatogram of base treated sample.

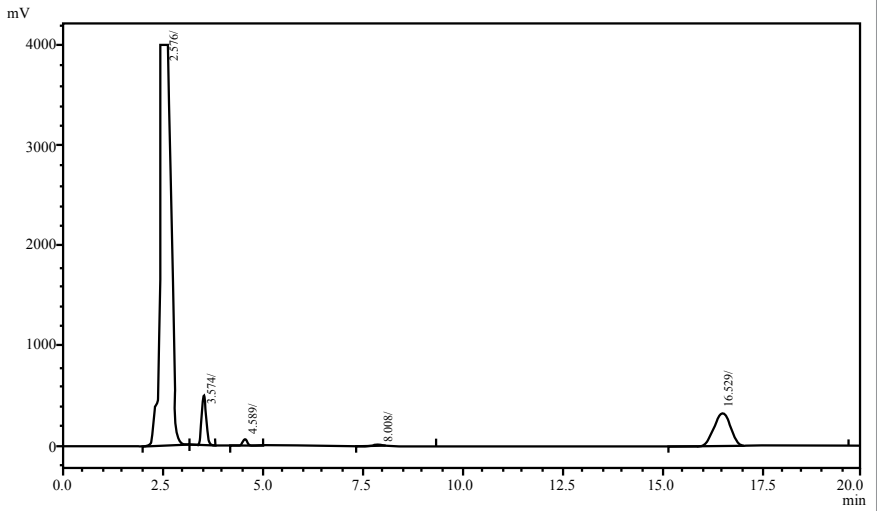

Figure 7: Typical Chromatogram of $\mathrm{H}_{2} \mathrm{O}_{2}$ treated sample.

degraded peaks of DBPN \& SBZ is the Clear evidence of base hydrolysis of carboxylic group [38]. Extremely high absorbance SBZ in peroxide treated sample (Figure 7) showing the sensitivity of carboxylic salt being oxidized.

\section{Conclusion}

The proposed new HPLC method described in this paper provides a simple, convenient and reproducible approach for the simultaneous identification and quantification of Dexibuprofen, Sodium Benzoate, 
Citation: Hasan N, Chaiharn M, Shah SN, Khalid H, Jabbar A (2013) Simultaneous Determination of NSAID and Antimicrobial Preservatives Using Validated RP-HPLC Method: An Application in Pharmaceutical and Clinical Laboratories. Pharm Anal Acta 4: 263. doi:10.4172/21532435.1000263

Page 6 of 7

\begin{tabular}{|c|c|c|c|c|c|c|c|c|c|}
\hline \multirow{2}{*}{ TEST (Claimed content) } & \multicolumn{7}{|c|}{ Interval } & \multirow{2}{*}{ Mean } & \multirow{2}{*}{ RSD $\%$} \\
\hline & Initial & 1Month & 2Month & 3Month & 4Month & 5Month & 6Month & & \\
\hline \multicolumn{10}{|c|}{ Studies at Accelerated $\left(40^{\circ} \mathrm{C}+75 \% \mathrm{H}\right)$} \\
\hline DBPN $(500 \mu \mathrm{g} / \mathrm{ml})$ & 100.351 & 99.961 & 99.476 & 99.265 & 98.971 & 98.432 & 98.157 & 99.044 & 0.794 \\
\hline SBZ $(12.5 \mu \mathrm{g} / \mathrm{ml})$ & 99.853 & 98.983 & 98.418 & 98.137 & 97.975 & 97.869 & 97.535 & 98.153 & 0.803 \\
\hline MP $(5 \mu \mathrm{g} / \mathrm{ml})$ & 99.991 & 98.615 & 98.315 & 98.158 & 97.518 & 97.410 & 97.112 & 98.160 & 0.989 \\
\hline $\mathrm{PP}(2.5 \mu \mathrm{g} / \mathrm{ml})$ & 99.614 & 99.741 & 99.534 & 98.614 & 98.198 & 97.536 & 97.418 & 98.665 & 1.002 \\
\hline \multicolumn{10}{|c|}{ Stability Studies at Long Term $\left(30^{\circ} \mathrm{C}+65 \% \mathrm{H}\right)$} \\
\hline DBPN $(500 \mu \mathrm{g} / \mathrm{ml})$ & 100.351 & 100.135 & 100.384 & 100.174 & 99.853 & 99.239 & 99.472 & 99.876 & 0.443 \\
\hline SBZ $(12.5 \mu \mathrm{g} / \mathrm{ml})$ & 100.516 & 99.623 & 99.398 & 98.938 & 98.917 & 98.374 & 98.126 & 98.896 & 0.644 \\
\hline MP $(5 \mu \mathrm{g} / \mathrm{ml})$ & 101.219 & 100.526 & 100.153 & 99.315 & 98.815 & 98.345 & 98.151 & 99.503 & 1.167 \\
\hline PP $(2.5 \mu \mathrm{g} / \mathrm{ml})$ & 101.648 & 101.689 & 100.235 & 99.958 & 99.461 & 98.432 & 98.012 & 99.919 & 1.432 \\
\hline
\end{tabular}

Table 5: Summary of stability studies.

\begin{tabular}{|c|c|c|c|c|c|c|c|c|c|}
\hline \multirow[b]{2}{*}{ Stress conditions } & \multirow{2}{*}{ Time / h } & \multicolumn{4}{|c|}{ Assay of active Substance } & \multicolumn{4}{|c|}{ Degradation (\%) } \\
\hline & & DBPN & SBZ & MP & PP & DBPN & SBZ & MP & PP \\
\hline Acid hydrolysis $(0.1 \mathrm{M} \mathrm{HCl})$ & 1 & $96.20 \%$ & $99.55 \%$ & $99.71 \%$ & $98.97 \%$ & $3.30 \%$ & $0.45 \%$ & $0.29 \%$ & $1.03 \%$ \\
\hline Base hydrolysis $(0.5 \mathrm{M} \mathrm{NaOH})$ & 1 & $99.57 \%{ }^{*}$ & $99.93 \%{ }^{*}$ & $96.49 \%$ & $98.51 \%$ & $0.43 \%^{*}$ & $0.07 \%^{*}$ & $3.51 \%$ & $1.49 \%$ \\
\hline Thermal $\quad\left(60^{\circ} \mathrm{C}\right)$ & 1 & $96.20 \%$ & $99.55 \%$ & $99.71 \%$ & $98.97 \%$ & $3.80 \%$ & $0.45 \%$ & $0.29 \%$ & $1.03 \%$ \\
\hline Oxidative hydrolysis $\left(35 \% \mathrm{H}_{2} \mathrm{O}_{2}\right)$ & 1 & $80.48 \%$ & $84.76 \%$ & $113.58 \%$ & $94.94 \%$ & $19.52 \%$ & $15.24 \%$ & $13.58 \%$ & $5.06 \%$ \\
\hline
\end{tabular}

Table 6: Summary of forced degradation results.

Methylparaben and Propylparaben in bulk, human serum, and pharmaceutical formulations with good separation and resolution. In addition, this method has the potential application to clinical research of drug combination. Analytical results are accurate and precise with good recovery and lowest detection limit values. In short, the developed method is simple, sensitive, easy, and efficient having short chromatographic time and can be used for routine analysis in QC laboratory and therapeutic monitoring.

\section{Refrences}

1. Budavari S (1996) The Merck index: an encyclopedia of chemicals, drugs and biologicals (12th edition). Whitehouse Station, $\mathrm{NJ}$ : Merck \& Co, USA.

2. Leising G, Resel R, Stelzer F, Tasch S, Lanziner A, et al. (1996) Physical aspects of dexibuprofen and racemic ibuprofen. J Clin Pharmacol 36: 3S-6S.

3. Evans AM (1992) Enantioselective pharmacodynamics and pharmacokinetics of chiral non-steroidal anti-inflammatory drugs. Eur J Clin Pharmacol 42: 237 256.

4. Dionne RA, McCullagh L (1998) Enhanced analgesia and suppression of plasma beta-endorphin by the $\mathrm{S}(+)$-isomer of ibuprofen. Clin Pharmacol Ther 63: 694-701.

5. Bonabello A, Galmozzi MR, Canaparo R, Isaia GC, Serpe L, et al. (2003) Dexibuprofen ( $\mathrm{S}+-$ isomer ibuprofen) reduces gastric damage and improves analgesic and antiinflammatory effects in rodents. Anesth Analg 97: 402-408

6. Albert KS, Gernaat CM (1984) Pharmacokinetics of ibuprofen. Am J Med 77: 40-46.

7. Laska EM, Sunshine A, Marrero I, Olson N, Siegel C, et al. (1986) The correlation between blood levels of ibuprofen and clinical analgesic response. Clin Pharmacol Ther 40: 1-7.

8. Soni MG, Taylor SL, Greenberg NA, Burdock GA (2002) Evaluation of the health aspects of methyl paraben: a review of the published literature. Food Chem Toxicol 40: 1335-1373.

9. Wei G (2009) Toxicity and Estrogen Effects of Methyl Paraben on Drosophila melanodaster. Food Science 30: 252-254.

10. Cashman AL, Warshaw EM (2005) Parabens: a review of epidemiology, structure, allergenicity, and hormonal properties. Dermatitis 16: 57-66.

11. Balan P, Nimila IC, Vanaja Rani M, Lakshmi Prasanna M, Rajasekar S (2011) A validated $\mathrm{Rp}-\mathrm{Hplc}$ Method for estimation of Dexibuprofen and Paracetamol in combined tablet dosage form. International Journal of PharmTech Research 3: 1293-1298.

12. Muralidharan S, Meyyanathan SN (2011) Development and validation of a HPLC and an UV spectrophotometric methods for determination of dexibuprofen in pharmaceutical preparations. ISRN Pharmaceutics 2011

13. Rudy AC, Anliker KS, Hall SD (1990) High-performance liquid chromatographic determination of the stereoisomeric metabolites of ibuprofen. J Chromatogr 532: 395-405.

14. Hindmarsh KW, John E, Asali LA, French JN, Williams GL, et al. (1983) Urinary excretion of methylparaben and its metabolites in preterm infants. J Pharm Sci 72: 1039-1041.

15. Lockwood GF, Wagner JG (1982) High-performance liquid chromatographic determination of ibuprofen and its major metabolites in biological fluids. $J$ Chromatogr 232: 335-343.

16. Mandal U, Das A, Agarwal S, Chakraborty U, Nandi U, et al. (2008) Bioequivalence study of two formulations containing $400 \mathrm{mg}$ dexibuprofen in healthy Indian subjects. Arzneimittelforschung 58: 342-347.

17. Dewland PM, Reader S, Berry P (2009) Bioavailability of ibuprofen following oral administration of standard ibuprofen, sodium ibuprofen or ibuprofen acid incorporating poloxamer in healthy volunteers. BMC Clin Pharmacol 9: 19.

18. Xu MJ, Zou C, H Chu J, Wu T, Liu SJ, et al. (2011) Pharmacokinetics and bioequivalence of single dose and multiple doses of immediate- and extendedrelease formulations of dexibuprofen in healthy Chinese subjects. Int $\mathrm{J}$ Clin Pharmacol Ther 49: 237-246.

19. Zhang X, Liu X, Gong T, Sun X, Zhang ZR (2012) In vitro and in vivo investigation of dexibuprofen derivatives for CNS delivery. Acta Pharmacol Sin 33: 279-288.

20. Greenblatt DJ, Arendt RM, Locniskar A (1983) Ibuprofen pharmacokinetics: use of liquid chromatography with radial compression separation Arzneimittelforschung 33: 1671-1673.

21. Shabir GA (2010) A new validated HPLC method for the simultaneous determination of 2-phenoxyethanol, methylparaben, ethylparaben and propylparaben in a pharmaceutical gel. Indian J Pharm Sci 72: 421-425.

22. Safra J, Pospisilova M (2008) Separation and determination of ketoprofen, methylparaben and propylparaben in pharmaceutical preparation by micellar electrokinetic chromatography. J Pharm Biomed Anal 48: 452-455.

23. Atemnkeng MA, Marchand E, Plaizier-Vercammen J (2007) Assay of artemether, methylparaben and propylparaben in a formulated paediatric antimalarial dry suspension. J Pharm Biomed Anal 43: 727-732.

24. Satinsky D, Huclova J, Ferreira RL, Montenegro MC, Solich P (2006) Determination of ambroxol hydrochloride, methylparaben and benzoic acid in pharmaceutical preparations based on sequential injection technique coupled with monolithic column. J Pharm Biomed Anal 40: 287-293.

25. Rebbeck C, Hammond R, Wong J, Nair L, Raghavan N, et al. (2006) Solid- 
Citation: Hasan N, Chaiharn M, Shah SN, Khalid H, Jabbar A (2013) Simultaneous Determination of NSAID and Antimicrobial Preservatives Using Validated RP-HPLC Method: An Application in Pharmaceutical and Clinical Laboratories. Pharm Anal Acta 4: 263. doi:10.4172/21532435.1000263

phase extraction and HPLC analysis of methylparaben and propylparaben in a concentrated antibiotic suspension. Drug Dev Ind Pharm 32: 1095-1102.

26. Chocholous P, Satinsky D, Solich P (2006) Fast simultaneous spectrophotometric determination of naphazoline nitrate and methylparaben by sequential injection chromatography. Talanta 70: 408-413.

27. Ali MS, Ghori M, Khatri AR (2006) Stability indicating simultaneous determination of domperidone (DP), methylparaben (MP) and propylparaben by high performance liquid chromatography (HPLC). J Pharm Biomed Anal 41: 358-365

28. Saad B, Bari MF, Saleh MI, Ahmad K, Talib MK (2005) Simultaneous determination of preservatives (benzoic acid, sorbic acid, methylparaben and propylparaben) in foodstuffs using high-performance liquid chromatography. $J$ Chromatogr A 1073: 393-397.

29. Matysova L, Hajkova R, Sicha J, Solich P (2003) Determination of methylparaben, propylparaben, triamcinolone acetonide and its degradation product in a topical cream by RP-HPLC. Anal Bioanal Chem 376: 440-443.

30. Kreuz DM, Howard AL, Ip D (1999) Determination of indinavir, potassium sorbate, methylparaben, and propylparaben in aqueous pediatric suspensions. J Pharm Biomed Anal 19: 725-735.

31. Hajkova R, Solich P, Dvorak J, Sicha J (2003) Simultaneous determination of methylparaben, propylparaben, hydrocortisone acetate and its degradation products in a topical cream by RP-HPLC. J Pharm Biomed Anal 32: 921-927.
32. Ali MS, Chaudhary RS, Takieddin MA (1999) Simultaneous determination of metronidazole benzoate, methylparaben, and propylparaben by highperformance liquid chromatography. Drug Dev Ind Pharm 25: 1143-1147.

33. Kokoletsi MX, Kafkala S, Tsiaganis M (2005) A novel gradient HPLC method for simultaneous determination of ranitidine, methylparaben and propylparaben in oral liquid pharmaceutical formulation. J Pharm Biomed Anal 38: 763-767.

34. Pongcharoenkiat N, Wittayanukulluk A, Hem SL (2003) Determination of methylparaben in o/w emulsions by solid-phase extraction and highperformance liquid chromatography. J Cosmet Sci 54: 47-52.

35. Ma M, DiLollo A, Mercuri R, Lee T, Bundang M, et al. (2002) HPLC and LCMS studies of the transesterification reaction of methylparaben with twelve 3 to 6-carbon sugar alcohols and propylene glycol and the isomerization of the reaction products by acyl migration. J Chromatogr Sci 40: 170-177.

36. ICH-Q2B (2005) Guideline for Industry, Q2B Validation of Analytical Procedure: Methodology. International Conference on Harmonisation, Food and Drug Administration, U.S. Department of Health and Human Services.

37. Hasan N, Chaiharn M, Mirani ZA, Qambrani NA (2013) Validated RP-HPLC method for determination of dexibuprofen: Application in pharmaceutical dosage and human serum. Analytical Chemistry: An Indian Journal. 12: 283290.

38. Brown WH, Foote CS, Iverson BL, Anslyn E (2008) Organic Chemistry, Chapter 17: Carboxylic Acids. 